Arab World English Journal (AWEJ) Special Issue on Covid 19 Challenges April 2021

DOI:https://dx.doi.org/10.24093/awej/covid.28

\title{
Female Saudi University Students' Perceptions of Online Education Amid COVID-19 Pandemic
}

\author{
Nasrin Altuwairesh \\ College of Languages \& Translation \\ King Saud University \\ Riyadh- Kingdom of Saudi Arabia \\ Email: naltuwairesh@ksu.edu.sa
}

Received: $3 / 6 / 2021$

Accepted: 4/21/2021

Published: 4/24/2021

\begin{abstract}
The outbreak of the COVID-19 pandemic has wreaked havoc and caused world-wide disruptions to daily activities, including education. Numerous mitigation measures were taken to slow down the rapid spread of this pandemic. The situation, subsequently, entailed utilizing technology to ensure the continuation of the educational process. The abrupt shift to online education presented significant challenges to teachers and learners alike. Uncovering students' perceptions of their online education experience will help address and deal with these challenges. This study attempted to explore the perceptions of Saudi female undergraduate students of their online education experience amid the COVID-19 pandemic. The total of 241 female students at the College of Languages and Translation at King Saud University in Riyadh answered a multi-item online survey. The results revealed that many of the respondents were happy with their online learning experience, enjoyed learning online and looked forward to their online classes. However, when asked to compare online learning to brick-and-mortar classes, more than half of the participants stated that they prefer traditional, face-to-face learning. The results of this study also revealed that the significant problems students faced in online education related to staying motivated, technical issues and the absence of face-to-face interaction. Despite the many challenges they face when learning online, the most cited advantage for online education mentioned by the participants is that it is more convenient. The results also indicated that this education mode seemed to suit shy students more, as they stated that they participate and ask questions more in online classes.
\end{abstract}

Keywords: COVID-19 pandemic, female Saudi EFL university learners' perceptions, elearning; online education; technology

Cite as: Altuwairesh, N. (2021). Female Saudi University Students' Perceptions of Online Education Amid COVID-19 Pandemic. Arab World English Journal (AWEJ) Special Issue on Covid 19 Challenges (1)381-397. DOI: https://dx.doi.org/10.24093/awej/covid.28 
Arab World English Journal (AWEJ) Special Issue on Covid 19 Challenges April 2021

Female Saudi University Students' Perceptions of Online Education

Altuwairesh

\section{Introduction}

The COVID-19 pandemic has taken its toll on all aspects of our lives, including education. The only solution to ensure the continuation of education at all levels worldwide was to optimize the use of technology. Thus, in response to the pandemic, there was a complete shift to online instruction in most countries around the globe. The government of Saudi Arabia was proactive in implementing strict measures to contain and mitigate the spread of COVID-19. One of the earliest measures taken by the government of Saudi Arabia was the closure of schools and universities in March 2020, soon after the first COVID-19 case was confirmed in the country. This strict measure led to the abrupt move to electronic platforms, which caused some disorder to the educational process during that academic year, i.e., 2019-2020. Higher education institutes seemed to have suffered less than schools due to the availability of technological infrastructures, specifically learning management systems such as blackboard. Despite having such infrastructures, neither instructors nor students were ready for such an abrupt change.

However, when the new academic year started in September 2020, the students, along with instructors, have already had some previous experience dealing with online education. The general assumption was that things were settled, and students would not be facing as many issues with online education as in the previous semester. Many teachers, before the outbreak of the pandemic, have not embraced technology, either partially or entirely, in their classrooms for a variety of reasons. Thus, instructors with prior experience with online teaching were definitely at an advantage over their less tech-savvy colleagues. However, the situation has forced all educators to take technology onboard and move to online learning. Technology is, undoubtedly, a double-edged sword; if utilized effectively, it can be bliss; if otherwise, it can be a woe.

There was a pressing need to continue education amid the pandemic despite the disruption it has caused to educational systems worldwide. Research indicates that the impact of this shift to online education on university students has been profound, as there was a sharp drop in their satisfaction levels after the move to online courses (Means \& Neisler, 2020). Further, research proves that many aspects of the learning experience are influenced by the expectations and strategies adopted by instructors, such as student satisfaction and academic performance (Bailey \& Lee, 2020). Thus, uncovering students' perceptions of their online experience is expected to help instructors deal with the areas that need to be addressed when designing and implementing an online course. The study in hand attempted to reveal the perceptions of female Saudi undergraduate students about their experience with online education amid the pandemic.

\section{Literature Review}

\section{Technological Pedagogical Content Knowledge Model}

The tendency has been to only look at technology without paying closer attention to how it can be used effectively. Yet, the mere introduction of technology into education is never enough. There has been recent attention paid to the vital question of what teachers have to know for them to be better capable of incorporating technology appropriately into their classrooms (Mishra \& Koehler, 2006). The Technological Pedagogical Content Knowledge (henceforth TPCK) model was proposed by Mishra and Koehler (2006) and argues for the need for a complex and situated form of knowledge for the pedagogical use of technology in the classroom. This framework is based on the understanding that "teaching is a highly complex activity that 


\section{Arab World English Journal (AWEJ) Special Issue on Covid 19 Challenges April 2021}

draws on many kinds of knowledge" (p. 1020). In this model, the areas of content, pedagogy and technology, which are all essential for delivering good teaching, are treated as interrelated aspects of teaching, rather than separate entities (Mishra \& Koehler, 2006). Koehler and his colleagues (2007) have claimed that the relationship that holds between these three elements is dynamic and that "good teaching with technology requires understanding the mutually reinforcing relationships between all three elements taken together to develop appropriate, context-specific strategies and representations" (p.741). In other words, integrating technology effectively into teaching requires knowledge of the relationships that hold between these three elements (Koehler et al., 2007).

Content knowledge relates to knowledge about the subject matter that is taught. Pedagogical knowledge, on the other hand, is concerned with the profound knowledge about the practices and methods related to teaching and learning that cover all aspects of the educational process, including student learning, lesson planning, student evaluation, and classroom management. Technology knowledge relates to knowledge about both standard and advanced technologies and the skills needed to operate such technologies. The nature of technology knowledge (TK) tends to shift with time due to the changing nature of technology (Mishra \& Koehler, 2006). Further, this model relates to pedagogical techniques which utilize the use of technology to help teach subject matters constructively.

TPCK is a developing form of knowledge that goes beyond the individual components it consists of, i.e., technology, pedagogy, and content knowledge. TPCK represents the base on which good teaching with the use of technology depends and necessitates the understanding "of the representation of concepts using technologies" (Mishra \& Koehler, 2006, p.1029). The model simply argues that there can never be a single solution applied, to every course, teacher, or teaching method. Using new technology in any course is not like adding a new module to the same course. Effective integration of technology into teaching requires thoughtful consideration of the three elements of content, technology, and pedagogy, the complex relationships between these elements, and careful interweaving of these three primary sources of knowledge for teachers.

\section{Online Education}

The advent of technology has drastically changed practices in many aspects of human life. The history of online courses dates back to the 1980s, when the first course to be entirely online in the USA was delivered in 1981. The mid-1980s witnessed the first online graduate and undergraduate courses initiated by some schools and universities in the USA (Sun \& Chen, 2016). A cornerstone in the history of online education was the advent of the World Wide Web (WWW) in 1991, which facilitated the fast expansion and growth of online learning and teaching in the USA and worldwide (Sun \& Chen, 2016). Online education is defined as "a format used in learning when learners do not need to be in brick-and-mortar classrooms" (Sun \& Chen, 2016, p. 159). Means and Neisler (2020) define online instruction simply as "instruction offered via the internet to students using their own computers" (p. 4). The internet and the World Wide Web have brought about so many changes and advantages to education. With the new generation being digital natives, online learning is expected to be more exciting and appealing. 


\section{Arab World English Journal (AWEJ) Special Issue on Covid 19 Challenges April 2021}

Online education has its opportunities and advantages, such as opening up "new markets for higher education institutions" (Sun \& Chen, 2016, p. 160). Online learning further facilitates the education of adult learners, who have to juggle many responsibilities, such as work, family, and study. Moreover, the nature of online environments allows for more participation by shy students who are not in favour of face-to-face classes due to their personality traits. Further, research illustrates the many benefits online education presents to teachers and learners, including improved pedagogical practices, classroom engagement, self-confidence, and communication-skills (D. Bailey \& Lee, 2020). Other benefits relate to being more convenient than traditional brick-and-mortar classes, having more learner-centered activities, and increased student motivation. These benefits are witnessed due to a shift in the role played by instructors in virtual classrooms, from being mere disseminators of information to facilitators, which gives students more space for active participation in the learning process (D. Bailey \& Lee, 2020).

Online learning communities are thought to provide learners with an environment that enables them to learn effectively through the growth of three forms of presence, namely teaching, cognitive and social presence (Sun \& Chen, 2016). These three forms of presence are intertwined and interchangeable, with each presence playing a distinctive role. According to Sun and Chen (2016), many studies have demonstrated a strong correlation between social interaction and having a sense of community among learners and their impact on gaining a successful online learning experience. Further, a study conducted by Bailey and Card (2009) sought to reveal effective pedagogical practices for online teaching as perceived by fifteen experienced, awardwinning e-learning instructors. Based on the analysis of the one-to-one interviews, eight effective pedagogical practices for online education have been uncovered. These pedagogical practices include fostering relationships, engagement, timeliness, good communication, organization, effective utilization of technology, flexibility, and having high expectations.

Learning in online education can be synchronous, asynchronous, or a mixture of both. According to Means and Neisler (2020), several practices are recommended for online instruction, including having shorter activities, live sessions, frequent assessments, group projects, using 'breakout groups' during live classes, sending students personal messages to ask about how well they are doing in the course or to ensure that they can access course materials, using real-world examples when explaining course content, and setting tasks that would ask students to share what they have already learned and what they think they still need to learn in the course. Means and Neisler (2020) stated that incorporating a larger number of these recommended teaching practices resulted in better student satisfaction with their online learning experiences. Of these eight recommendations, the two practices which had the most significant impact on students were including personal messages to learners on how well they have been doing in the course and activities that require them to reflect on things they have already learned and those they still need to know (Means \& Neisler, 2020).

Redmond (2011) traced the journey of two academics as they transitioned from face-toface teaching to fully online education through archived online discussions as well as three onehour semi-structured interviews. The study helped shed light on the changing beliefs and pedagogical practices of these two academics over four years. Redmond (2011) summarized six frameworks that present a chronology of the various views on the roles played by instructors in 


\section{Arab World English Journal (AWEJ) Special Issue on Covid 19 Challenges April 2021}

online education. This summary led her to explain that despite using different names for the roles played by online teachers, the activities most commonly done by teachers include designing, management, organization, facilitation, and instruction. Another significant finding Redmond reached was that "the process of facilitating discussion appears to be a key role when teaching in the online space as it explicitly appears in five of the six frameworks" (p. 1053).

The move from face-to-face teaching to entirely online, Redmond (2011) says, challenges the roles and the expectations of learners and instructors alike. One major issue is that experienced instructors in traditional, brick-and-mortar education face an identity threat when moving to online classes, and in fact, "find themselves as novices or beginners when they first teach online" (p. 1052). The results of this study illustrated a shift in the way instructors would communicate with their students online, and how they designed their online courses, which took into account the students' experiences. The study also emphasized the significance of critical reflection, dialogue, and support during the instructors' journey from fully face-to-face to fully online teaching. The two instructors' progress during this pedagogical journey was enhanced by their reflections and their search for professional development. In fact, reflection, Hodges and Fowler (2020) state, "is situated as part of standard instructional design processes" (p.118).

Redmond (2011) further clarifies that the move to online education, whether partially or entirely, calls for changes introduced to practice and pedagogy to achieve effective learning outcomes. Other studies have demonstrated that the move to online education has shifted the role of an effective instructor to a facilitator rather than a teacher (C. J. Bailey \& Card, 2009). However, despite the many benefits of online learning, there must be challenges that have to be addressed when planning online education. Some of the challenges identified in the literature on online education include learners being distracted by other online content, having technical problems, and having barriers to authentic communication opportunities (D. Bailey \& Lee, 2020). The following section will shed light on some studies that have explored the challenges and opportunities presented by online education.

\section{Studies on Online Education}

Sun and Chen (2016) conducted a comprehensive review study on research and studies focusing on online learning. The authors reviewed literature reviews before 2008 and empirical studies after 2008. They aimed at shedding light on the good aspects and strategies of online learning and what makes it a success, thus providing a platform of discussions for both policymakers and educators on ways for developing and delivering effective online courses. This, Sun and Chen (2016) explain, is expected to offer whoever plans on embracing online education with best practices which will ultimately help them make informed decisions during the implementation process.

Sun and Chen's (2016) review revealed that developing a sense of community within an online environment is in fact a major challenge. To achieve this sense of community, the studies reviewed in this paper indicated the importance of promoting "social presence, interaction, and collaboration" (p. 170), with social presence mainly defined as students' participation. Thus, Sun and Chen (2016) argue that it is the duty of instructors and learners alike to "make a joint effort 


\section{Arab World English Journal (AWEJ) Special Issue on Covid 19 Challenges April 2021}

to get deeply involved in constructing interaction and collaboration between the instructor and students and among students to create an effective online learning community" (p.170). This article also reviewed the best pedagogical practices and strategies that are needed to achieve effective online teaching. A significant finding is that teachers, unquestionably, play a crucial role in online education through facilitating discussions, answering students' questions, designing course materials and assignments, and evaluating students' learning outcomes. As Sun and Chen (2016) bluntly put it, "technology does not - and cannot - replace the role and position of the teacher" (p. 171).

Cole, Shelley, and Swartz (2014) also conducted a three-year study that aimed to uncover the level of satisfaction of graduates and undergraduates at one university with online instruction. Their research demonstrated that students were moderately satisfied with online education and more satisfied with hybrid or partially online courses than fully online ones. The most cited reason for students' satisfaction with online education was "convenience," whereas the top reason for their dissatisfaction was "lack of interaction." Attempting to understand what makes online learning satisfactory to learners will help inform instructional design and curriculum development, which relates directly to student retention (Cole et al., 2014).

The "Survey of Student Perceptions of Remote Teaching and Learning" was developed to investigate the experiences of undergraduate students who were taking courses during the sudden transition to online instruction in response to the outbreak of COVID-19 (Means \& Neisler, 2020). The survey aimed at revealing the nature of the courses taught online during the pandemic, as well as the variety of challenges undergraduate students faced after the transition to online education, and the features of courses associated with higher levels of student satisfaction. This study surveyed a random sample of more than 1000 college students in the United States who witnessed the sudden transition from in-person to completely online learning during spring 2020. The results of Means and Neisler's study demonstrated a remarkable decrease in student satisfaction with their courses after the move to online instruction, with only $19 \%$ of the sample expressing their satisfaction with their online course experience. Sending students personal messages and asking them to reflect on what they have learned were cited as the two factors that had the most significant impact on student satisfaction with online courses. The results indicated that sending students personal messages on how they have been doing helped maintain their motivation, which was cited by the respondents as the most significant challenge they faced due to the move to online learning.

Means and Neisler's (2020) report also helped reveal some of the aspects that students thought suffered most due to the move online. These included collaborating with colleagues on course work, maintaining students' interest in the course, and making students feel like part of the class. The most significant challenges, according to the sample in this study, had to do with staying motivated, not knowing where to seek help with the course, and feeling unwell to participate in the course, either physically or emotionally. These were the challenges that related most closely to being overall satisfied with the course. Other themes that emerged from this study related to the learners' missing the presence of their instructors and colleagues while learning, not having immediate feedback from instructors on their performance, missing the 


\section{Arab World English Journal (AWEJ) Special Issue on Covid 19 Challenges April 2021}

Female Saudi University Students' Perceptions of Online Education

Altuwairesh

chance to understand course content better through discussions with peers. Some of the major issues reported by the participants related to internet connectivity, limited access to suitable computer devices, having other family and/or job responsibilities, and the unavailability of appropriate places at home for doing the course work.

Bailey and Lee (2020) also attempted to shed light on the challenges and opportunities online education presents for EFL university instructors. This survey study illustrated several key findings due to the unique situation the world is going through at the time of COVID-19 pandemic. One key finding stated that having experience teaching online was positively related to expected communication channels and activity selection. Further, instructors with no experience teaching online expressed frustration with online education and other related digital teaching activities. This group of instructors also perceived more potential problems when teaching online. The two other groups, on the contrary, perceived fewer obstacles due to their use of a variety of activities and using more communication channels to deliver such activities.

The benefits and challenges to students that have been reported were quite similar across the three surveyed groups, i.e., the no-, low-, and high- experience groups. Some of the benefits for students included having more time to answer, making use of online writing tools, and practicing writing. On the other hand, the students' challenges the survey revealed included: having to collaborate with other students, becoming distracted, and attending online meetings. Further, it is during such difficult times that "the need to make online educational opportunities easy to access takes on new importance because many learners might not be in an emotional state to focus on learning" (Carter et al., 2020).

A study conducted by Cohen and Baruth (2017) attempted to characterize online learners and examine the relationship between learners' personalities on the one hand and how satisfied they were with fully online academic courses on the other hand. The study also looked into the possibility of predicting learners' satisfaction with online courses according to their personalities. The results of Cohen and Baruth's research demonstrated that being open to experiences and conscientious significantly predicted students' levels of satisfaction with online learning.

In the Saudi context, Mahyoob (2020) attempted to investigate the challenges faced by EFL learners at tertiary level amid the pandemic through the use of an online survey. The study focused on learners' views on the sudden transition to online education during the early days of the shift to online mode. The sample included 184 students, both male and female respondents. The results demonstrated that most of the challenges the students faced had to do with technical issues, mainly problems with blackboard and internet connection, which had its impact on exams, tasks, and class attendance. Further, a major obstacle reported by the students was communicating effectively with their instructors during online education. The findings of this study further showed that most participants were not completely satisfied with online learning.

Based on the review of relevant literature presented above, the study in hand aimed at examining the perceptions of female EFL learners at tertiary level amid the COVID 19 


\section{Arab World English Journal (AWEJ) Special Issue on Covid 19 Challenges April 2021}

Female Saudi University Students' Perceptions of Online Education

Altuwairesh

pandemic. Uncovering students' perceptions of their educational experiences, particularly novel experiences, will thus inform pedagogy and lead to better teaching practices.

\section{Methods}

The present article reports on a case study that attempted to reveal the perceptions of Saudi female, undergraduate students of online education during the COVID-19 pandemic. The respondents were 241 female, undergraduate students aged 20-24, enrolled at the Department of English Language and Translation, the College of Languages and Translation at King Saud University in Riyadh. They have completed at least five levels of their undergraduate degree. The researcher purposefully targeted students from higher levels, i.e., levels six, seven, and eight, because they would have already had enough experience with brick-and-mortar classes at university level and would therefore be able to compare their university educational experience before and after the outbreak of the pandemic and the consequent shift to online education.

The respondents had to fill in a five-Likert scale, multi-item, online questionnaire, which consisted of several closed-ended items and two open-ended ones. The closed-ended items related mainly to whether the students enjoyed online learning, were happy with their experience, and whether they preferred virtual or traditional classroom learning. On the other hand, the two open-ended questions aimed at investigating the advantages and disadvantages of online learning from the students' point of view. The response rate to this survey was relatively high, as it reached more than $80 \%$ of the targeted group, which could be an indication of the students' eagerness to voice their opinions on online learning. Unlike the study conducted by Mahyoob (2020), which gathered data on students' perceptions on online education during the early days of the shift to virtual classes, the present study gathered data during the second semester in the history of entirely online learning in Saudi Arabia. Students, have already had experience with online education and the technological issues that come about with it, and are thus less likely to report on major technological issues.

The survey items sought to reveal the students' perspectives on online education, including the challenges they face during online learning as well as the advantages they see in this mode of learning. Based on what has been mentioned above, this study aimed at answering the following research question:

What are the perceptions of female Saudi undergraduate students of online education amid the COVID-19 pandemic?

The data collected through the closed-ended questionnaire items were analysed descriptively. Descriptive analysis of the results fulfils the purpose of this article, as it provides a simple and clear interpretation of the data. In other words, descriptive analysis satisfies the aim of providing the reader with a clear idea of the participants' perceptions of online education. On the other hand, the responses to the two open-ended questionnaire items were analysed thematically. 
Arab World English Journal (AWEJ) Special Issue on Covid 19 Challenges April 2021

Female Saudi University Students' Perceptions of Online Education

Altuwairesh

\section{Findings}

I am happy with my online learning experience

241 responses

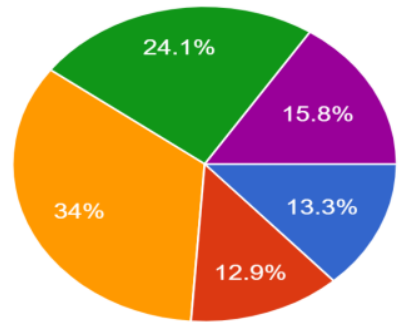

Strongly disagree

Disagree

Neutral

Agree

Strongly agree

Figure 1 Being happy with online learning experience

As Figure one indicates, around $40 \%$ of the participants said they are happy with their online learning experience. Only $22 \%$ clearly stated that they are not satisfied with their online learning experience, whereas $34 \%$ of the respondents were neutral about it.

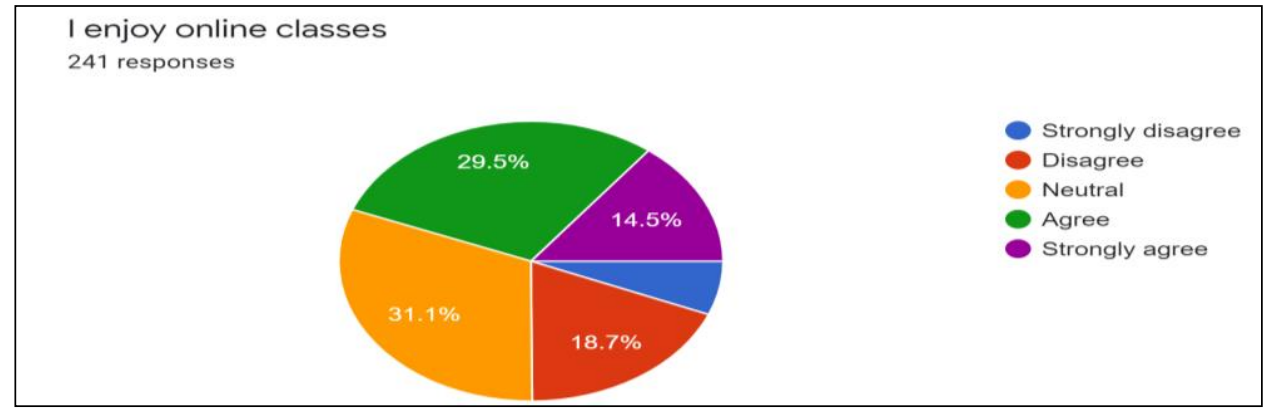

Figure 2 Enjoying online classes

Figure two presents another finding, which is relatively consistent with the previous one, that $44 \%$ of the participants said that they enjoy online classes, $31 \%$ were neutral about it. In comparison, only $25 \%$ did not enjoy online learning.

I look forward to my online classes

241 responses

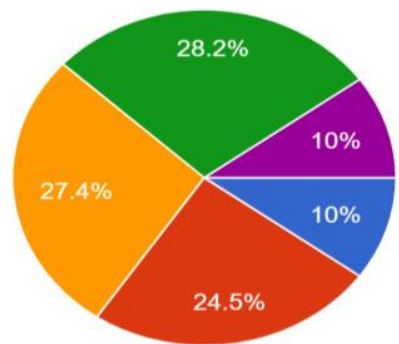

Strongly disagree

Disagree

Neutral

Agree

Strongly agree

Figure 3 Looking forward to online classes

When asked about whether they look forward to their online classes or not, $38 \%$ said they looked forward to them, $27 \%$ were neutral, whereas $35 \%$ said they did not look forward to their online classes, as shown in Figure three above. 
Arab World English Journal (AWEJ) Special Issue on Covid 19 Challenges April 2021

Female Saudi University Students' Perceptions of Online Education

Altuwairesh

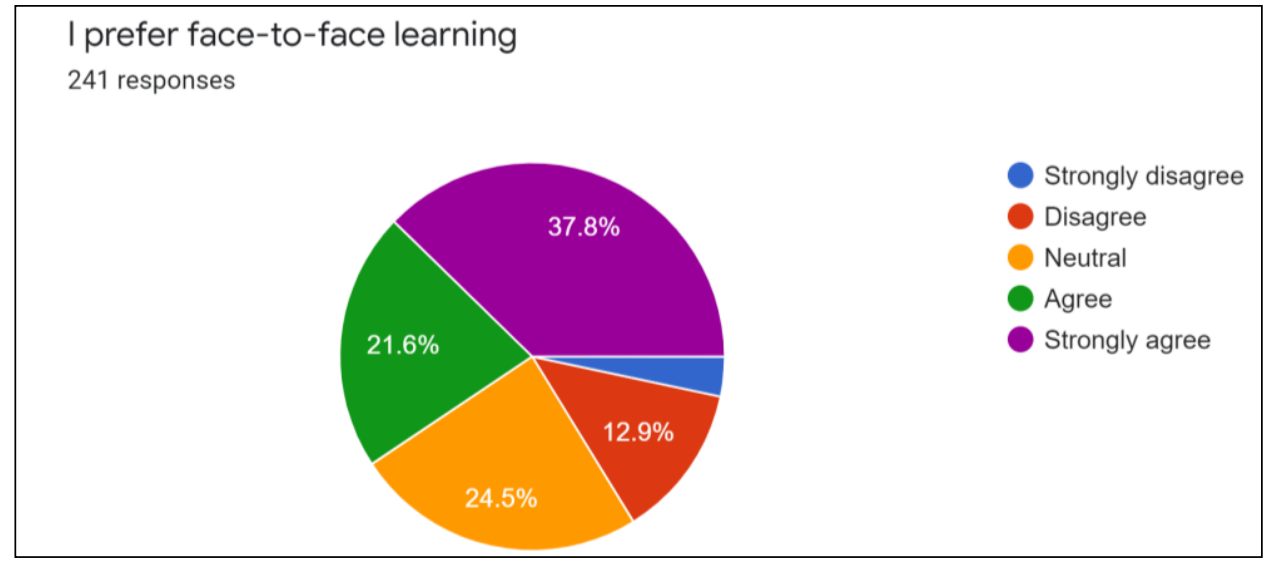

Figure 4 Preference for face-to-face learning

According to Figure four, around $60 \%$ of the participants prefer face-to-face learning, nearly $25 \%$ were neutral about it, and only $16 \%$ do not prefer face-to-face learning.

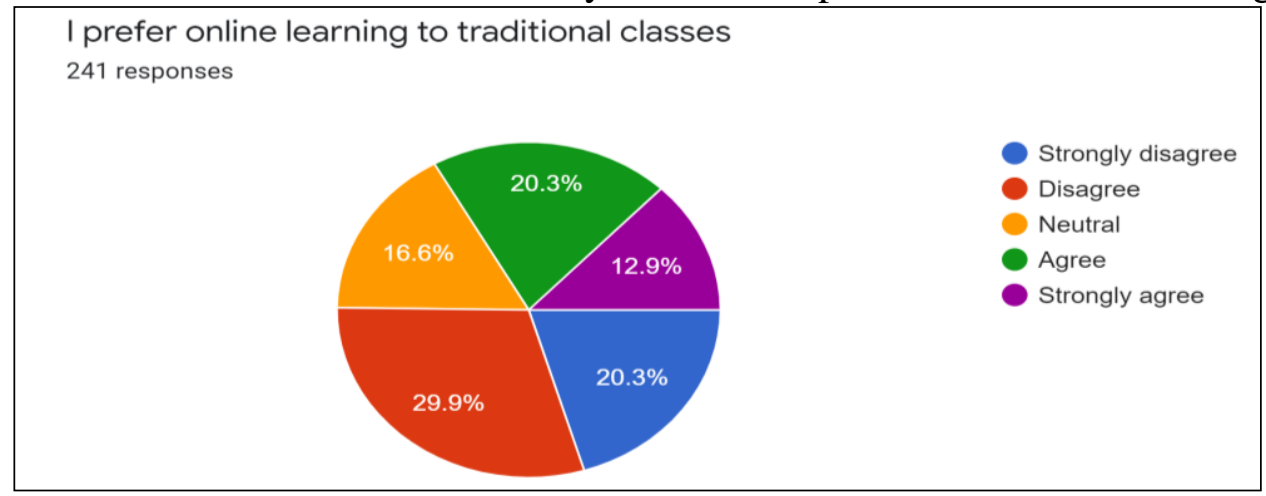

Figure 5 Preference for traditional classes

Figure five shows that $33 \%$ of the respondents prefer online learning, $16 \%$ were neutral about it, whereas half do not like online learning. This finding corroborates the previous one.

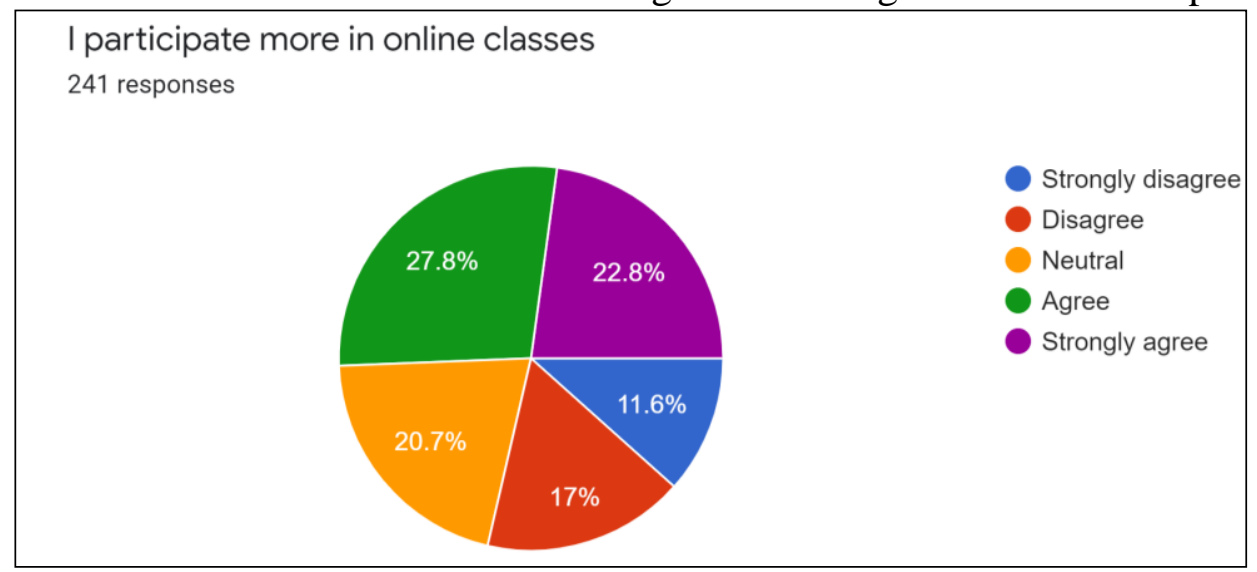

Figure 6 Participating more in online classes

When asked about participation, nearly half of the respondents agree that they participate more in online classes, as shown in Figure six, while 20\% were neutral about this statement, and 28\% disagreed with it. 


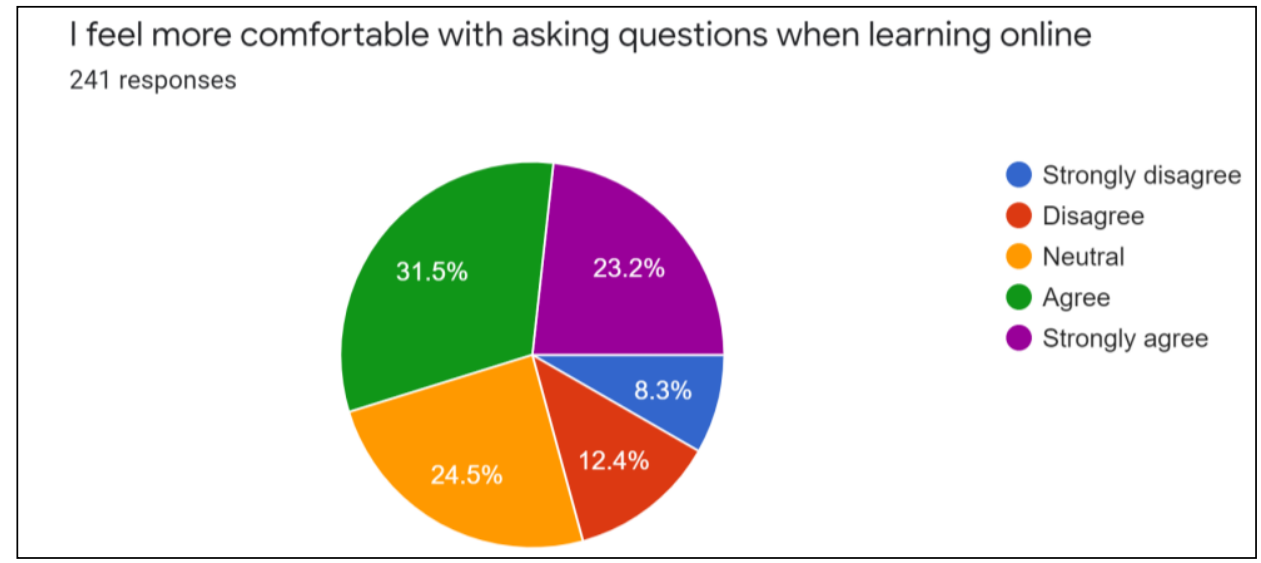

Figure 7 Feeling more comfortable with asking questions when learning online Figure seven reveals that almost $55 \%$ of the sample students feel more comfortable asking questions when learning online, nearly $25 \%$ were neutral, and $20 \%$ did not agree with this statement.

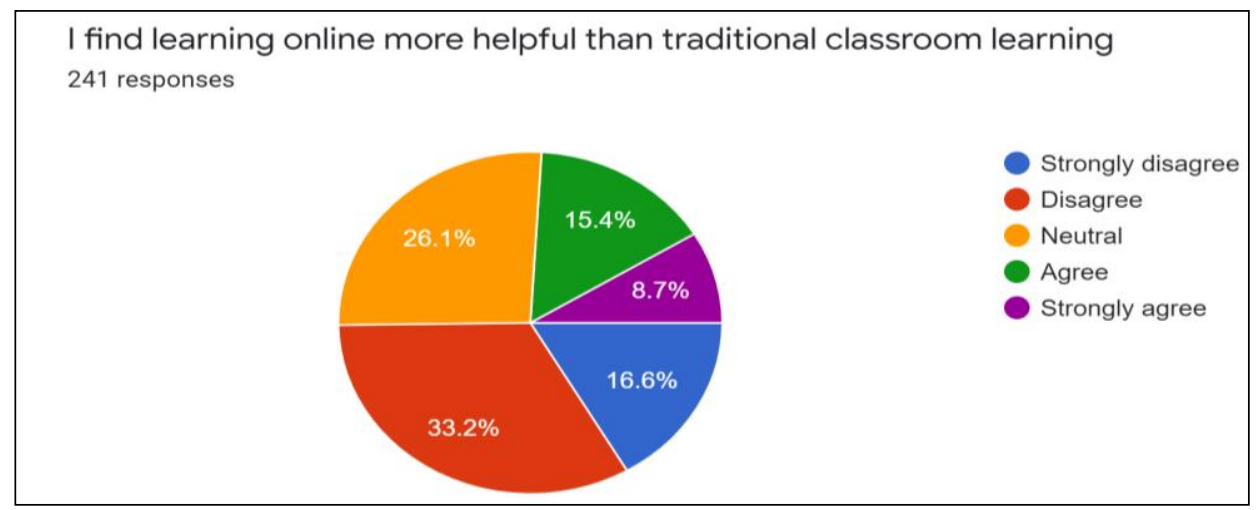

Figure 8 online learning being more helpful than traditional learning Figure eight demonstrates that almost $50 \%$ disagree with finding online learning more helpful than traditional classroom learning, whereas $24 \%$ agreed to this statement, while $26 \%$ were neutral about it.

I believe I learn more in an online environment

241 responses

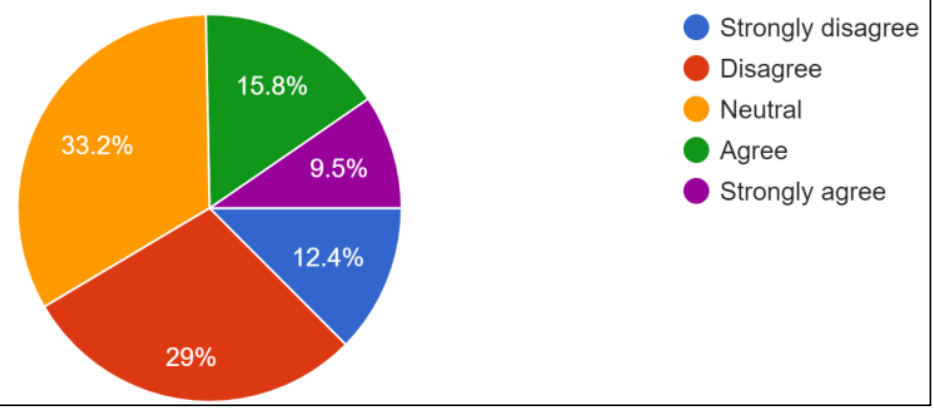

Figure 9 Learning more in an online environment 
Arab World English Journal (AWEJ) Special Issue on Covid 19 Challenges April 2021

Female Saudi University Students' Perceptions of Online Education

Altuwairesh

When asked about whether they believe they learn more in an online environment or not, $25 \%$ of the participants agreed to learning more online, whereas $41 \%$ disagreed, and $33 \%$ were neutral about this statement, as indicated in Figure nine above.

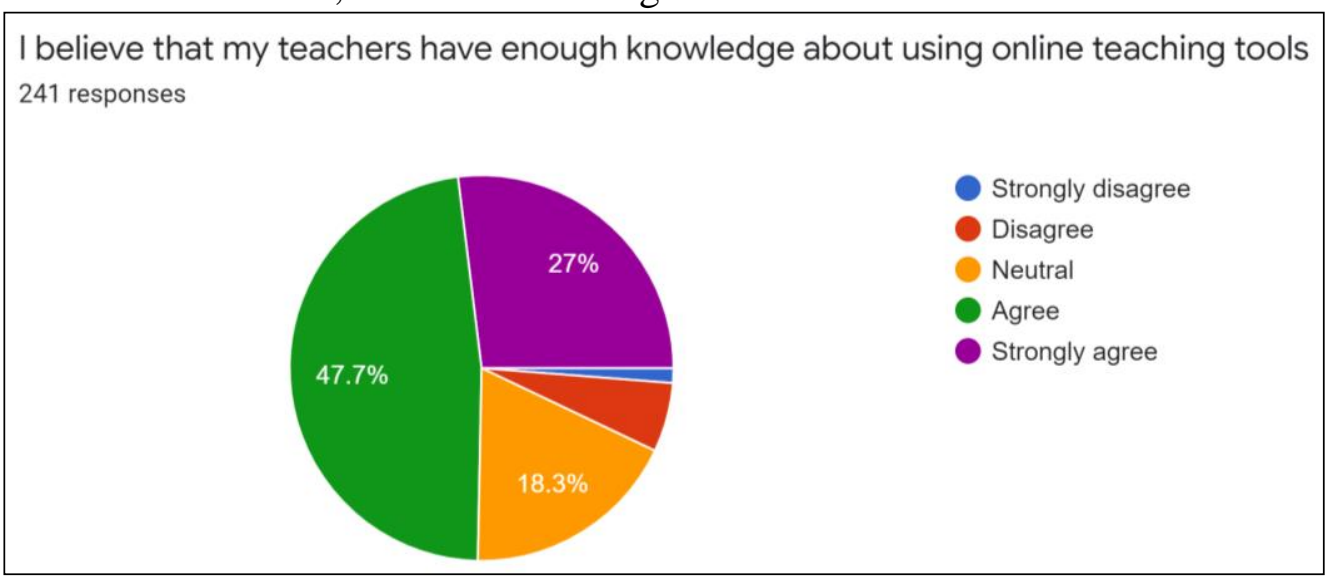

Figure 10 Instructors possessing good technological knowledge

A positive finding shown in Figure 10 above indicates that most participants, i.e., nearly $75 \%$ of them, agree that their teachers have enough knowledge about using online teaching tools, $18 \%$ were neutral. In contrast, only $7 \%$ disagreed with this statement.

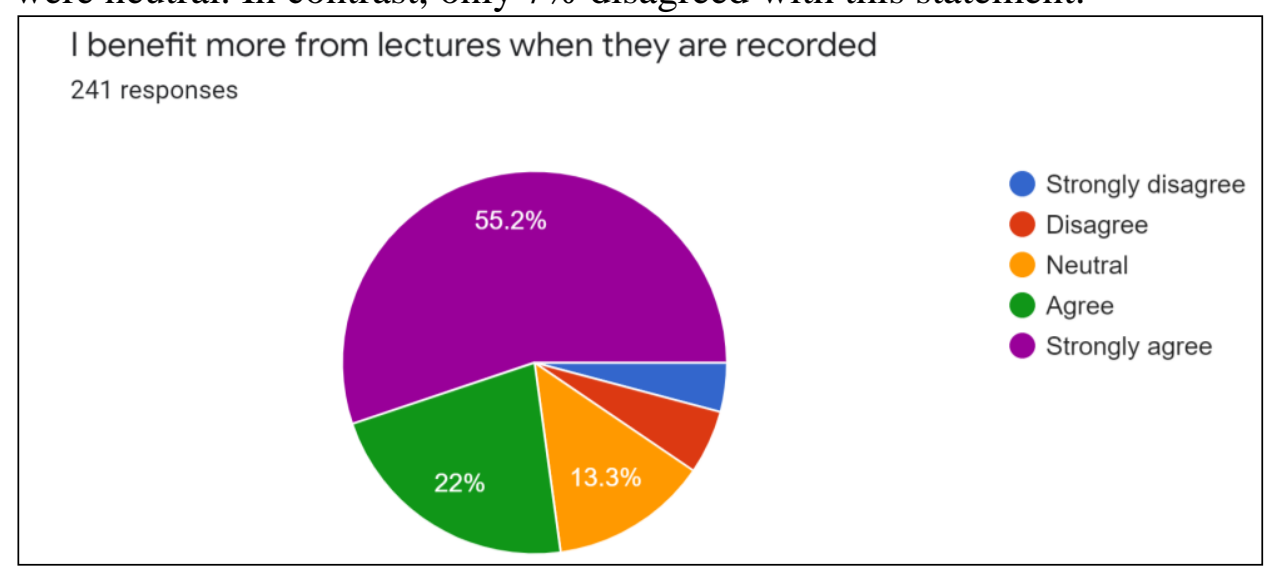

Figure 11 Benefiting more from recorded lectures

When asked about recorded lectures, 77\% agreed that they benefit more from lectures when recorded, $13 \%$ were neutral, whereas only $9 \%$ disagreed with this statement, as shown in Figure 11 above.

Further, the survey attempted to uncover the problems students face with online learning. According to their responses, the participants' biggest issues were staying motivated to do well in their courses, having problems with internet connection, and the absence of face-to-face interaction.

The questionnaire also included two open-ended questions on the advantages and disadvantages of online learning from the students' point of view. The students' responses to these two questions were analyzed thematically. The themes that emerged from their responses to the question about the advantages of online learning were mainly two themes that related to convenience and learners' traits. The majority of responses to the question on the advantages of online learning stated that it was convenient in terms of saving time, being more comfortable and 
Arab World English Journal (AWEJ) Special Issue on Covid 19 Challenges April 2021

Female Saudi University Students' Perceptions of Online Education

Altuwairesh

flexible, having recorded lectures, and not having to commute to university. Examples of the students' responses that illustrate this theme are:

allow us to have enough time to complete homework or projects

saving more time instead of going a far distance to university

the most important for every student is TIME, and online learning saves time from transportation and the way to and from university

it is a time-saver; you do not have to wake up so early to get ready, have breakfast and then go to the university

it saves a lot of time (commute time) that I can now use productively

online learning is more flexible

attending classes from your home comfort is, of course, an advantage

better time management + flexibility

some lectures are recorded so I can go back to them

attending classes on time easily

The second most cited advantage had to do with learners' traits, especially ones related to students' shyness and how learning online helped them participate more despite being shy. Some responses that demonstrate this theme included:

much easier to participate

being able to participate without feeling shy

feeling free to ask questions and answering even if it is wrong

sending my questions without talking or being recognized

no fear or shyness to participate or ask

ask questions comfortably

I can talk with my teacher without feeling shy

that I am able to ask questions and participate more than in real life because I get very anxious

interact with teachers comfortably

in my presentations I become less nervous

I have more confidence to talk to my teachers

When asked about the disadvantages of online learning, the students mainly mentioned technological problems, the learning environment with the absence of face-to-face interaction, and its effect on their levels of motivation and focus, having too many distractions, and sometimes more tasks to fulfill. The most cited disadvantage by the participants was technological issues, particularly internet connection problems, sound quality, and lagging in blackboard.

A central recurrent theme was the online learning environment and how it affected the students' ability to focus, stay motivated, and having too many distractions around them during online classes. Some mentioned that they struggled to find a quiet place to attend their classes. Further, some participants commented on how isolating the online learning experience is, how badly they miss attending university, socializing with others, and interacting with them face-toface. Such comments are proof enough for the desperate need to create a sense of community 
Arab World English Journal (AWEJ) Special Issue on Covid 19 Challenges April 2021

Female Saudi University Students' Perceptions of Online Education

Altuwairesh

among the learners when delivering an online course. The following were some of the participants' actual responses:

create a sense of isolation

missing the face-to-face interaction- not getting to know the teachers personally-

loss of motivation and concentration

absence of interaction with teachers and students

never motivated that it kills the excellent student I have in me

I get distracted easily

it's boring, so we lack attention and get distracted

I do not feel motivated. It does not seem like a real class

not being able to stay focused during classes

finding a quiet place

Another disadvantage of online learning given by the participants related to having more tasks to do after the abrupt transition to online education, thus being overloaded with assignments, quizzes, and other coursework. On the other hand, a few responses mentioned by the participants related to the teachers themselves, either not knowing students, being inconsiderate of them and their time, or not knowing how to handle technological problems efficiently. Interestingly enough, the response of one of the participants was, "I think there are no disadvantages." This response, in particular, is intriguing as it reflects how diverse the views of students are regarding their experience with online learning.

\section{Discussion and Implications}

This study revealed several findings about the perceptions of female undergraduate students of EFL online education amid the COVID-19 pandemic. One major finding is that many of the respondents were happy with their online learning experience, enjoyed learning online and looked forward to their online classes. Yet, when asked to compare online learning to brick-andmortar classes, more than half of the participants stated that they prefer traditional, face-to-face learning. The former result could be justified when relating it to another finding of this study which indicated that students believed their instructors possessed good technological knowledge. Instructors knowing how to deal with technological tools efficiently results undoubtedly in a better learning experience. This finding is contrary to the results reported by Mahyoob (2020) who stated that most students in his study were not satisfied with their online learning experience and that they had many issues interacting and communicating with their instructors effectively. Research done on online education has emphasised the key role instructors play in online learning (Sun \& Chen, 2016; Means \& Neisler, 2020).

Another major finding is that the students' most cited advantage for online education was 'convenience,' which was also the most cited reason for students' satisfaction with online instruction in other studies (Cole et al., 2014; Bailey \& Lee, 2020). The results also showed that the online education mode suited a group of students, particularly those who are shy. This finding is also supported in the literature, as Sun and Chen (2016) explained that the nature of online environments allowed for more participation by shy students who do not prefer attending face-to-face classes due to their personality traits. On the contrary, the most cited disadvantages for online education by the respondents in this study were the lack of face-to-face interaction and 


\section{Arab World English Journal (AWEJ) Special Issue on Covid 19 Challenges April 2021}

the effect it had on their ability to stay motivated and focused, as well as having technical problems, particularly with internet connection. These challenges were similar to the challenges reported by students in other studies, such as the ones by Means and Neisler (2020), Cole et al. (2014), Mahyoob (2020)and Bailey and Lee (2020).

Having revealed students' struggle and the many problems they have to face when attending classes online requires that instructors become more considerate of them and the issues they have with online learning. We all realize that attending classes online, amidst these difficult times, can be pretty demotivating. Thus, instructors should show empathy to students and provide them with the help and support they need. The advice for instructors is to vary the teaching techniques and strategies used during online education to address the needs of different learning styles. Following a 'one size fits all' approach when teaching online could lead to limited participation and classroom engagement (Bailey \& Lee, 2020), which will undoubtedly have a negative impact on the learners' motivation.

To facilitate the development of pedagogical practices, instructors should get into the habit of reflecting on their professional practice. Reflection entails that by the end of the online course, instructors would mainly ask themselves about the things that went well and those which did not, thus they would carry on doing the things that went well and look for better ways to deliver course items that did not work well. Further, as part of the reflection process, instructors can ask the students who have completed the course requirements for their views on the contents of the course and teaching strategies used during the course. Instructors might also face problems with course design and planning, particularly ones who are not knowledgeable enough about online class delivery (Bailey \& Lee, 2020). Knowing that this type of problem is typical and looking for solutions, such as reaching out for help, can lead to better online teaching practices. To understand the online teaching and learning processes better, Redmond (2011) advises academics to develop the practice of critically questioning their pedagogical practices and to hold discussions with their peers on such matters. For this to be successful, she says, "there needs to be a climate of support, the participants need to be receptive to feedback from their peers, and they should engage meaningfully in reflective practice" (p.1058). As previously mentioned, personal reflections and the search for professional development helped enhance the instructors' progress during their pedagogical journey in Redmond's study.

The educational process has gone through a tectonic change caused by the unfolding events that accompanied the outbreak of the pandemic. This time of COVID-19 and the complete shift to online education has been a catalyst for change and has seen the introduction of technological innovations in teaching and learning. However, with learners being at the center of the educational process, an important question posed by this study is whether students are considered winners or losers of this change? Are we to consider them winners, given that most of the new generation, if not all, are digital natives? A simple answer to this question, supported by the results of this study and other similar studies, is that technology indeed has a lot to offer, yet it is not always perfect, and it can never substitute the critical role teachers play in the educational process.

The COVID-19 pandemic has brought about many new challenges to both learners and teachers. Further, the pandemic and the sudden transition to online education has led educators to 


\section{Arab World English Journal (AWEJ) Special Issue on Covid 19 Challenges April 2021}

redefine their roles and teaching practices in virtual classrooms. Online education is all about the learners; thus, more should be done to reveal the factors that motivate learners to take part actively in an online course, given that active participation results in better learning outcomes. Education is inherently a social matter, therefore, more of the social element should be added to break the ice, engage the students, and increase their motivation during online classes. University instructors should modify their roles in virtual classrooms from being mere disseminators of information to facilitators. This presumably will help ensure the involvement and engagement of learners in the learning process, and when this is achieved, their motivation will most likely increase.

\section{Conclusion}

In conclusion, based on the students' responses to this survey study, blended learning seems to be a promising option that would suit learners of different learning styles. In postpandemic EFL classrooms, blended learning would apparently be a better approach that would facilitate integrating technology into the educational process. Despite that the sudden transfer to online education amid the COVID-10 pandemic has caught us unaware and caused considerable disruption, this experience can be viewed as a blessing in disguise. It opened instructors' eyes to novel ways of delivering classroom instruction and has led them to learn about new virtual resources and activities. The shift to online education has been an excellent opportunity for professional development which should never end; instead, the experience has proven to instructors that there is no limit to professional development and that they can always learn something new and embrace new technologies in EFL classrooms.

\section{AuthorAbout the Author:}

Nasrin Altuwairesh is Assistant Professor at the College of Languages and Translation (COLT) at King Saud University in Riyadh/ Saudi Arabia. She holds an MA and a PhD in Education/ TESOL from the University of Leeds/ United Kingdom. She has taught several translation courses at COLT. Her research interests focus on language teaching, the teaching of translation and training translators. ORCID id: https://orcid.org/0000-0003-0823-0743

\section{References}

Bailey, C. J., \& Card, K. A. (2009). Effective pedagogical practices for online teaching: Perception of experienced instructors. Internet and Higher Education, 12(3-4), 152-155. https://doi.org/10.1016/j.iheduc.2009.08.002

Bailey, D., \& Lee, A. (2020). Learning from experience in the midst of covid-19: Benefits, challenges, and strategies in online teaching. Call-Ej, 21(2), 176-196.

Carter, R. A., Rice, M., Yang, S., \& Jackson, H. A. (2020). Self-regulated learning in online learning environments: strategies for remote learning. Information and Learning Science, 121(5-6), 311-319. https://doi.org/10.1108/ILS-04-2020-0114

Cohen, A., \& Baruth, O. (2017). Personality, learning, and satisfaction in fully online academic courses. Computers in Human Behavior, 72, 1-12. https://doi.org/10.1016/j.chb.2017.02.030

Cole, M. T., Shelley, D. J., \& Swartz, L. B. (2014). Online instruction, e-learning, and student satisfaction: A three year study. International Review of Research in Open and Distance Learning, 15(6), 111-131. https://doi.org/10.19173/irrodl.v15i6.1748

Hodges, C. B., \& Fowler, D. J. (2020). The COVID-19 Crisis and Faculty Members in Higher 
Arab World English Journal (AWEJ) Special Issue on Covid 19 Challenges April 2021

Female Saudi University Students' Perceptions of Online Education

Altuwairesh

Education: From Emergency Remote Teaching to Better Teaching through Reflection. International Journal of Multidisciplinary Perspectives in Higher Education, 5(1), 118122.

Koehler, M. J., Mishra, P., \& Yahya, K. (2007). Tracing the development of teacher knowledge in a design seminar: Integrating content, pedagogy and technology. Computers and Education, 49(3), 740-762. https://doi.org/10.1016/j.compedu.2005.11.012

Mahyoob, M. (2020). Challenges of e-Learning during the COVID-19 Pandemic Experienced by EFL Learners. Arab World English Journal, 11(4), 351-362. https://doi.org/10.24093/awej/vol11no4.23

Means, B., \& Neisler, J. (2020). Suddenly Online: A National Survey of Undergraduates During the COVID-19 Pandemic. https://doi.org/10.1145/763940.763929

Mishra, P., \& Koehler, M. (2006). Technological Pedagogical Content Knowledge: A Framework for Teacher Knowledge. Teachers College Record, 108(6), 1017-1054. http://one2oneheights.pbworks.com/f/MISHRA_PUNYA.pdf

Redmond, P. (2011). From face-to-face teaching to online teaching: Pedagogical transitions. ASCILITE 2011 - The Australasian Society for Computers in Learning in Tertiary Education, January 2011, 1050-1060.

Sun, A., \& Chen, X. (2016). Online education and its effective practice: A research review. Journal of Information Technology Education: Research, 15, 157-190. https://doi.org/10.28945/3502 